\title{
Study of modal analysis based on fluid-structure interaction
}

\section{Estudo da análise modal baseado no acoplamento fluido-estrutura}

\author{
M. PEGORARO \\ mauriciopegoraro85@gmail.com.br \\ F. A. A. GOMES a \\ franciscogomes@utfpr.edu.br \\ P. R. NOVAK a \\ novak@utfpr.edu.br
}

\begin{abstract}
In this work, a coupled fluid-structure problem is approached, comparing the result with the modal analysis of a structure. The objective of this work is to analyze the physical phenomenon of fluid-structure interaction of a flexible structure. For this, the coupled problem solved using an Arbitrary Lagrangean-Eulerian (ALE) approach. As support for solving the mathematical equations of coupled problem, ANSYS $\otimes$ physical analysis software was used. An experimental modal analysis, using the Rational Fractional Polynomial method was developed for a small scale steel structure, and the result of this was compared with the result obtained from the model simulated in the software. Their vibration modes and natural frequencies obtained by numerical modeling were validated experimentally. Whit the numerical modeling of the modal analysis of a structure experimentally validated, attempted to analyze the dynamic behavior of the structure when it is subjected to a load due to a fluid-flow through a coupled fluidstructure problem. The results presented in this work show that the structure subjected to loads due to the fluid-flow, moves according to its vibration modes.
\end{abstract}

Keywords: modal analysis, fluid-structure interaction.

\section{Resumo}

Neste trabalho é abordado um problema acoplado fluido-estrutura, sendo comparados os resultados com a análise modal de uma estrutura. $\mathrm{O}$ objetivo do trabalho consiste em analisar o fenômeno físico da interação fluido-estrutura de uma estrutura flexível. Para tal, o problema acoplado é resolvido utilizando uma abordagem Lagrangeana-Euleriana Arbitrária (ALE). Como apoio para resolução das equações matemáticas do problema acoplado, foi utilizado o "software" de análises físicas ANSYS $®$. Uma análise modal experimental, utilizando o método "Rational Fractional Polynomial", foi desenvolvida para uma estrutura de acco em escala reduzida, e o resultado desta foi comparado com o resultado obtido no modelo simulado no "software". Seus modos de vibração e frequências naturais obtidos na modelagem numérica foram validados experimentalmente. Com a modelagem numérica da análise modal de uma estrutura validada experimentalmente, buscou-se analisar o comportamento dinâmico da estrutura quando ela está sujeita a uma carga devido a um escoamento, através de um problema acoplado fluido-estrutura. Os resultados presentes neste trabalho mostram que a estrutura sujeita a cargas devido ao escoamento, movimenta-se conforme seus modos de vibração.

Palavras-chave: análise modal, problema acoplado fluido-estrutura.

Universidade Tecnológica Federal do Paraná, Pato Branco, PR, Brasil. 


\section{Introduction}

Coupled fluid-structure problems play a key role in the development of various engineering areas. In civil engineering, emphasis is put on dams, water reservoirs, fuel tanks, marine platforms, turbines, piping systems and also in structures in general. In addition, this approach is also used to solve biomedicine problems, such as cadiovascular behavior in the human body.

In cases in which the presence of a moving fluid, when in contact with a structure, causes the dynamic behavior of the fluid to change, the problem must be handled with a fluid-structure approach. In this type of approach, the formulations describe and model the problem in an integrated manner, where the solutions to the structure and fluid domains are coupled.

Coupled fluid-structure problems can be classified in several ways, according to some references, for example, Souza Jr. [1] and Gilbert [2]. But, according to Zienkiewicz and Taylor [3], there are two major classes of coupled problems: class (I) contains the problems in which, by an imposition of the boundary condition of the fluid-structure interface region, the coupling occurs, using different discretizations in the domains, as they are different physical situations; while class (II) contains the problems in which severa domains overlap totally or partially over each other, and although the equations describe different physical phenomena, the coupling takes place through differential equations.

Initially developed for application in aquatic structures, the analyses of coupled fluid-structure problems began as soon as the Titanic tragedy occurred in 1912. Junger [4] shows the submarine project for studies with this method during World War I. In the field of mechanical engineering, Tabarrok [5] expanded the studies for problems of acoustic-structural vibration, also contributing to aerospace engineering.

Regarding conventional building structures, research can bring benefits, mainly in relation to the development of safer projects, with new materials and a lower cost. According to Leitão [6], structural calculation norms simplify second order effects on structures, which can cause large displacements in them and consequently their imminent collapse. These second-order effects can often be caused by a gust of wind, especially in steel structures, which are light and not very rigid.

In the last decades, through the finite element method (FEM) and the finite volume method (FVM), coupled fluid-structure problems have been solved in several ways and with good precision in the results. Despite this, there are several numerical techniques different from each other for solving this type of problem. What most influences the way the problem is addressed is the way the fluid domain is modeled. The fluid variable is associated with several quantities, such as pressure, displacement, potential velocity and/ or potential displacement, while the unknown for the solid is the displacement field, (Everstine, [7]). Depending on the variable chosen for the fluid domain, the problem might not be solved, that is, each of the possible variables for the fluid presents applications restricted to a certain type of problem.

Usually, the structure is modeled by the finite element method, for any type of structure, such as beams, plates, solids or more complex bodies, such as shells or blunt bodies, these last structures being studied by Gomes [8]. In relation to the fluid domain, the flow is generally discretized using the finite volume method. Soares Jr. [9] combined several numerical techniques, applying the finite element method to the structure and the boundary element method (BEM) to the flow, in this way contemplating the problem of fluidstructure interaction.

Bazilevs et. al. [10] were inspired by the analytical solutions and developed a beautiful work, consisting in the development of the governing equations of the phenomenon, aside from presenting methods and applications using computational mechanics.

According to Zienkiewicz and Bettess [11], there are two classical ways of approaching a coupled fluid-structure problem, Lagrangian and Eulerian. According to these authors, the Eulerian formulation is characterized by using one of the following quantities as unknowns for the fluid domain: the pressure or displacement potential, which generates asymmetric matrices for resolution. However, the Lagrangian formulation considers the displacement as a variable for both domains, fluid and structure, the fluid being considered as an elastic solid without shear modulus. The disadvantage of the Lagrangian approach is that the fluid is considered without a shear modulus, which can generate illegitimate results due to the large number of degrees of freedom generated by this hypothesis.

Most of the methods studied by scientists dealing with coupled fluid-structure problems have some limitations for solids, such as the consideration of linear elastic behavior with constant elasticity, constituted of a homogeneous, isotropic material and subjected to small displacements. For the fluid, it must be incompressible, without viscosity and the process is adiabatic.

For problems where the solid has large displacements, such as a structure being excited at a frequency close to its natural frequency or a flexible structure, and where the fluid is Newtonian and may have viscosity, Wall and Ramm [12] present a method based in the Arbitrary Lagrangian-Eulerian (ALE) method. Dettmer and Peric [13] and Teixeira and Awruch [14] also have research related to this approach that is worth highlighting.

An arbitrary consideration including the two approaches, i.e., the Arbitrary Lagrangian-Eulerian (ALE) approach, is used to explain the deformation of the fluid domain resulting from the displacement of the flexible structure.

These techniques presented require the execution of a specified sequence of resolution components, with communication between data at the boundaries, transferring the data from the structure to the fluid and vice versa (Dettmer and Peric, [13]). Often, these methods do not have much accuracy, unless a time constraint is imposed, which should be small enough for data transfer to take place effectively (Wall and Ramm, 12).

These diverse coupled fluid-structure problem solving techniques focus on the development of numerical methods, which are being incorporated by various multi-physical analysis software.

The numerical methodology used in this work uses different discretizations among the domains, the finite element method being used in the discretization of the structure and the finite volume method being used in the discretization of the flow. The approach used is the Arbitrary Lagrangian-Eulerian (ALE) method, where coupling is done in the fluid-structure interface region by imposing the relevant boundary conditions.

In the next sections of this work, it will be shown that this numerical methodology brings satisfactory results, comparing the resolution of 
a problem of experimental modal analysis and structural dynamics with the behavior of this structure when subjected to oscillations of the lift coefficient due to the flow on its exterior. A specific focus of this work is to show which solution procedure is best suited to solve the coupling of a flexible structure with a Newtonian fluid. To aid in the resolution of mathematical formulations, the Ansys ${ }^{\circledR}$ software was used, both for the modal analysis of the structure under study and for the resolution of the coupled fluid-structure problem.

\section{Governing equations}

\subsection{Incompressible newtonian fluid with a moving domain}

The Navier-Stokes equations representing the incompressible Newtonian fluid are written in terms of the equations of continuity and Newton's second law of motion. These equations can be written as:

$\rho\left(\dot{\boldsymbol{u}}+\left(\nabla_{\widehat{\boldsymbol{x}}} \boldsymbol{u}\right)(\boldsymbol{u}-\widehat{\boldsymbol{v}})-\boldsymbol{F}\right)-\nabla_{\widehat{\boldsymbol{x}}} \cdot \boldsymbol{\sigma}=0 \quad \forall(\widehat{\boldsymbol{x}}, t) \in \Omega \times D$

$\nabla_{\hat{x}} \cdot \boldsymbol{u}=0 \quad \forall(\widehat{\boldsymbol{x}}, t) \in \Omega \times D$

where $\rho$ represents the density of the fluid, $F$ the volume force vector, $\sigma$ the Cauchy tensor. The time interval of interest is denoted by $\mathrm{D}=[0, \mathrm{t}]$.

An essential feature of the problems that are addressed in this article is the movement of the boundary of the fluid in contact with the flexible solid. The geometry of the fluid domain may change significantly during the time domain of interest. Therefore, it is convenient to formulate the problem in the ALE approach, where conservation laws are expressed considering this movement of the boundary. Thus, the derivative in time of the velocity $u$ is described as:

$\frac{\mathbf{d} \boldsymbol{u}}{\mathbf{d} t}=\nabla_{\widehat{x}} \boldsymbol{u}(\boldsymbol{u}-\widehat{v})+\dot{u}$

where $\hat{v}=\partial \hat{x} / \partial t$ is the velocity at the referred fluid-structure iteration point.

The operator $\nabla_{\hat{\mathbb{X}}}(\circ)$ denotes the derivatives with respect to the current $\hat{x}$ coordinates reference. The expression ú corresponds to the change in particle velocities observed by an observer traveling with a point in the reference system. The velocity difference $u-\hat{v}$ is called the relative velocity.

\subsubsection{Boundary conditions for the fluid}

The boundaries $\Gamma$ of $\Omega$ can be divided into subsets $\Gamma_{\mathrm{q}}, \Gamma_{\mathrm{g}}$ and $\Gamma_{\mathrm{f}-\mathrm{s}}$, where the indices q, g represent, respectively, the boundary at the input and output of the fluid domain. The index $\mathrm{f}-\mathrm{s}$ represents the boundary of the fluid in contact with the structure. The boundary conditions can be prescribed in these subsets, as follows:

$\boldsymbol{u}=\boldsymbol{q} \quad \forall(\widehat{\boldsymbol{x}}, t) \in \Gamma_{q} \times D$

$\boldsymbol{\sigma} \widehat{\boldsymbol{n}}=\boldsymbol{g} \quad \forall(\widehat{\boldsymbol{x}}, t) \in \Gamma_{g} \times D$

$\boldsymbol{u}={ }^{\prime} \boldsymbol{d} \quad \forall(\widehat{\boldsymbol{x}}, t) \in \Gamma_{f-s} \times D$

$(\boldsymbol{u}-\widehat{\boldsymbol{v}}) \cdot \widehat{\boldsymbol{n}}=0 \quad \forall(\widehat{\boldsymbol{x}}, t) \in \Gamma_{f-s} \times D$ $\boldsymbol{p}_{\mathrm{f}}+\boldsymbol{p}_{s}=\boldsymbol{\sigma} \widehat{\boldsymbol{n}}+\boldsymbol{p}_{s}=0 \quad \forall(\widehat{\boldsymbol{x}}, t) \in \Gamma_{f-s} \times D$

The values of $q$ and $g$ are prescribed and represent, respectively, the velocity of the fluid at the inlet and the pressure of the fluid at the exit of the domain by the respective boundary. The boundary condition at the fluid-structure interface $\Gamma_{\mathrm{f}-\mathrm{s}}$ is shown in equation (6), which means that there is a non-slip condition. Also at the boundary $\Gamma_{\mathrm{f}-\mathrm{s}}$ there is a need to satisfy the condition prescribed in (7), which represents that the boundary $\Gamma_{\mathrm{f}-\mathrm{s}}$ of the fluid with the structure should be coincident with the contour of the deformed structure, with each step of time. The pressure equilibrium along the fluid-structure interface is expressed by the ratio (8), where the values $p_{s}$ and $p_{f}$ represent the pressure vectors exerted by the fluid at the interface with the flexible structure.

\subsection{Dynamics of the structures}

The conservation of energy in a solid can be expressed in its spatial condition as follows:

$\rho(" \boldsymbol{d}-\boldsymbol{F})-\nabla \cdot \boldsymbol{\sigma}=0$

where $\rho$ is the density of the deformed solid, the vector "d represents the displacement of the structure, while the body forces are given by vector $F$. Here the Cauchy tensor is also represented by $\sigma$. For simplification, this work deals with a structure with linear elastic behavior.

As in the boundary of the fluid domain, the outline of the structure can be subdivided into three subsets $\Gamma_{q}, \Gamma_{g}$ and $\Gamma_{f-s}$, its boundary conditions being as follows:

$\boldsymbol{d}=\boldsymbol{q} \quad \forall(\widehat{\boldsymbol{x}}, t) \in \Gamma_{q} \times D$

$\boldsymbol{\sigma n}=\boldsymbol{g} \quad \forall(\widehat{\boldsymbol{x}}, t) \in \Gamma_{q} \times D$

$' \boldsymbol{d}=\boldsymbol{u} \quad \forall(\widehat{\boldsymbol{x}}, t) \in \Gamma_{q} \times D$

$\boldsymbol{p}_{\mathrm{f}}+\boldsymbol{p}_{s}=\boldsymbol{\sigma} \widehat{\boldsymbol{n}}+\boldsymbol{p}_{s}=0 \quad \forall(\widehat{\boldsymbol{x}}, t) \in \Gamma_{f-s} \times D$

where the values $\mathrm{q}, \mathrm{g}$ and $\mathrm{n}$ are prescribed and signify, respectively, the displacement, the traction vector and the normal unit vector to the contour surface of the structure. Conditions (12) and (13) clearly come in accordance with conditions (6) and (8) of the fluid, respectively.

Initially, the configuration of the structure is known as $d=0$ and ' $\mathrm{d}=0 \forall \mathrm{x} \in \Omega$ at $\mathrm{t}=0$.

\subsection{Modal analysis - RFP method}

Modal analysis is a way of analyzing the vibration parameters of a structure through experimental methods (Ewins, [15]). The RFP (Rational Fraction Polynomial method) is serving as the standard for modal analysis in the frequency domain. Schwarz and Richardson [16] state that this method is a curve fitting technique applied in the frequency domain and is easy to apply across any frequency range. The numerical modeling of the RFP method is given by:

$H(\omega)=\frac{\sum_{K=0}^{N} b_{k}(j \omega)^{K}}{\sum_{K=0}^{2 * m o d o s} a_{K}(j \omega)^{K}}$, 
where $H(\omega)$ is the frequency response function (FRF), $\omega$ is the natural frequency, ak and $\mathrm{K}$ start at zero and end at a value equal to twice the number of modes. For the numerator, bk and $\mathrm{K}$ start at zero and end at $\mathrm{N}$.

For the determination of the peaks and zeros, the equation used is the following:

$H(\omega)=\frac{\prod_{K=0}^{N}\left(j \omega-z_{K}\right)^{K}}{\prod_{K}^{2 * \operatorname{modos}}\left(j \omega-P_{K}\right)^{K}}$,

here, the parameters $\mathrm{Pk}$ and $\mathrm{K}$ take values between one and two modes of vibration. In the numerator we have the interval from zero to $\mathrm{N}$ for the variables $\mathrm{zk}$ and $\mathrm{K}$.

For waste, the following is used:

$H(\omega)=\sum_{K=1}^{\text {modos }}\left(\left(R_{K} / j \omega-P_{K}\right)+\left(R_{K}^{*} / j \omega-P_{K}^{*}\right)\right)$

where the intervals of $\mathrm{Pk}, \mathrm{Rk}$ and $\mathrm{K}$ start at one and end at a value equal to the number of modes.

\section{Methodology}

With the objective of analyzing the physical phenomenon involved in the fluid-structure interaction, the numerical methods used to solve the problem will not be discussed here, but rather, the model that best fits this analysis will be demonstrated.

The resolution scheme of the coupled fluid-structure problem using an Arbitrary Lagrangian- Eulerian approach (ALE) is shown in figure 1 and can be referred to as a two-way method because the two domains are solved separately.

The variable adopted for the resolution of the fluid domain is the pressure. In the first step, the governing equations for the fluid are solved, in order to transfer the pressure value at the fluid-solid interface. This pressure generates a certain displacement in the structure, which is the variable chosen for the structure domain. In sequence, the dynamics equations of the structures are solved for the solid, and the displacement is transferred to the solid-fluid interface. From there, the first step is finalized, and the next ones follow the same logic. For each step, the equations are resolved until the response has converged to the chosen parameter or a predetermined maximum number of iterations has been reached. In this work, the influence of the oscillation of vortices generated in the flow of the fluid in a flexible structure, with constant linear modulus of elasticity, was studied. For this, the fluid domain is relatively large in relation to the structure, trying to simulate a structure in an open environment. Since only the region close to the interface between the two domains is influenced by the displacement of the structure, the domain of the fluid can be divided into two parts. In the distant region of the structure, an Eulerian approach is used to solve the Navier-Stokes equations, while in the region close to the structure, a Lagrangian approach is used, that is, an Arbitrary Lagrangian-Eulerian (ALE) approach is used for the fluid domain. In light of the foregoing, it is understood that this methodology is the most appropriate when it is necessary to consider a flexible structure. In order to solve the problem of fluid mechanics, the computational code FLUENT [17] will be used, which solves the field of fluid flow through the finite volume method, whereas for the structure, the finite element method is used.

\subsection{Vibration of a beam induced by a flow}

In this section, the objective is to show a methodology that is consistent to couple the fluid problem with the structure problem, verify the effect of the influence of the fluid flow on an object, and also the effect that a pressure load variation (through the analysis of the lift coefficient) exerts on a structure. It is intended to couple the two types of problems, transferring the effect of the flow to the structure, and the effect of the displacement of the structure caused by that flow to the domain of the fluid.

For the comparison of the fluid-structure interaction model, the problem is presented where a flow induces the vibration of a flexible beam. This problem was solved by several authors, such as Wall and Ramm [12]; Dettmer and Peric [13], Bazilevs et. al. [10] among others. The problem was modeled and the result compared to that available in the literature.

A rigid and stationary cube-shaped body is submerged in a flow of a Newtonian fluid, generating vortices in the fluid, which, in contact

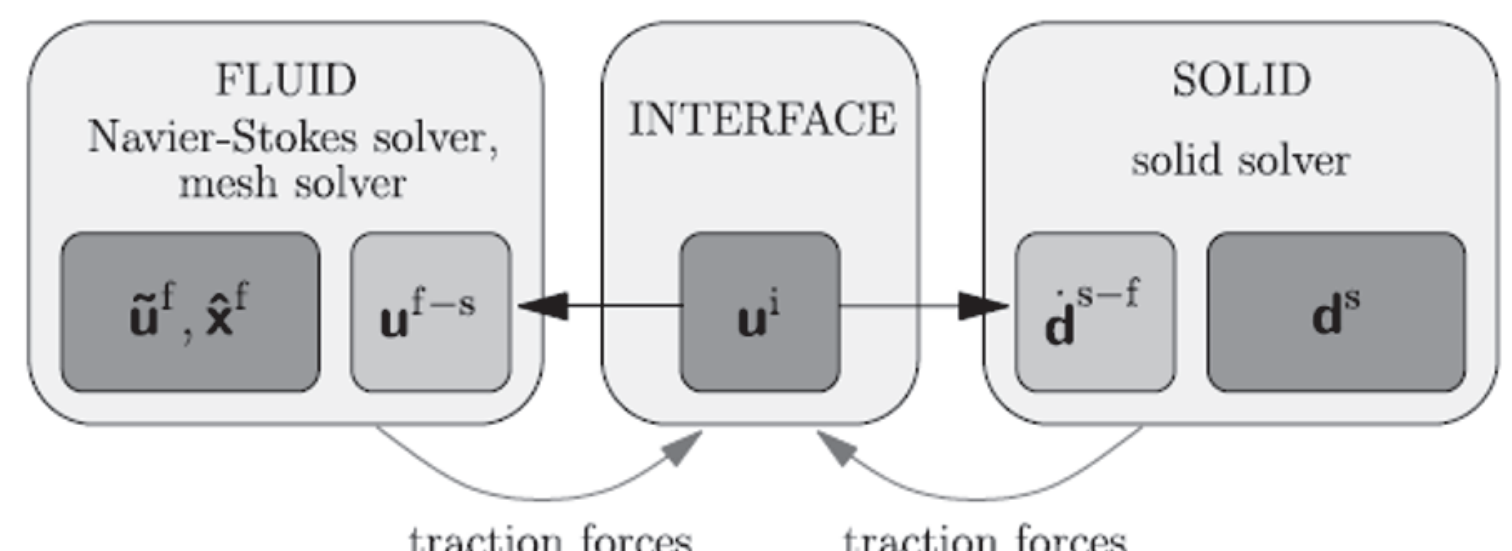

\section{Figure 1}

Resolution scheme for fluid-structure interaction

Source: Dettmer e Peric, [13] 


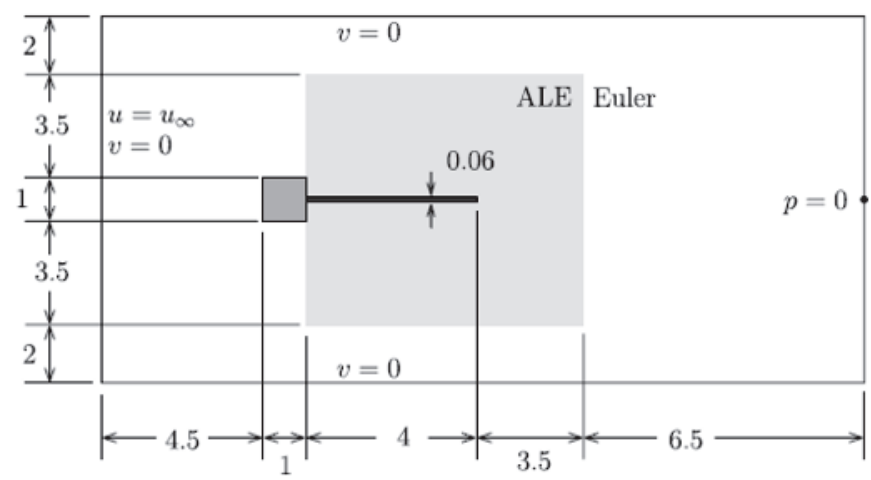

\section{Figure 2}

Vibration of a beam induced by a fluid flow: boundary conditions and geometry

Source: Dettmer e Peric, [13]

with the beam, cause the lift coefficient on it to oscillate and consequently make it vibrate. The scheme is shown in figure 2 , where the dimensions are in centimeters $(\mathrm{cm})$.

In relation to the approach and boundary conditions, an Arbitrary Lagrangian-Eulerian (ALE) approach was adopted, where in the region of the fluid domain close to the structure, mobile meshes were used to follow the structure displacement. The properties adopted for the fluid and the solid were the same as those used by Wall and Ramm [12], the viscosity and the density of the fluid respectively being $\mu_{\mathrm{f}}=1,82 \times 10^{-4} \mathrm{~kg} /(\mathrm{m} . \mathrm{s})$ and $\rho_{\mathrm{f}}=1,18 \times 10-3 \mathrm{~kg} / \mathrm{m}^{3}$. The density, modulus of elasticity and the Poisson coefficient of the solid are, respectively, $\rho_{\mathrm{s}}=0,1 \mathrm{~kg} / \mathrm{m}^{3}, E=2,5 \times 106 \mathrm{~N} / \mathrm{m}^{2}$ and $v=0,35$. It is a solid with low rigidity and, therefore, large deformations are expected in the beam. The objective of this approach is to demonstrate the strong coupling between fluid and structure when this approach (ALE) is adopted. The constant velocity of the flow at the input of the domain is $u_{\infty}=51,3 \mathrm{~m} / \mathrm{s}$ in the $\mathrm{x}$-direction. This means that the Reynolds number for the case is $\operatorname{Re}=\left(\rho_{f} D \mu_{\infty}\right) / \mu_{f}=333$, where $D$ is the hydraulic diameter of the rigid body of square geometry that is submerged in the flow with the intention of generating vortices, which induce the vibration in the beam.

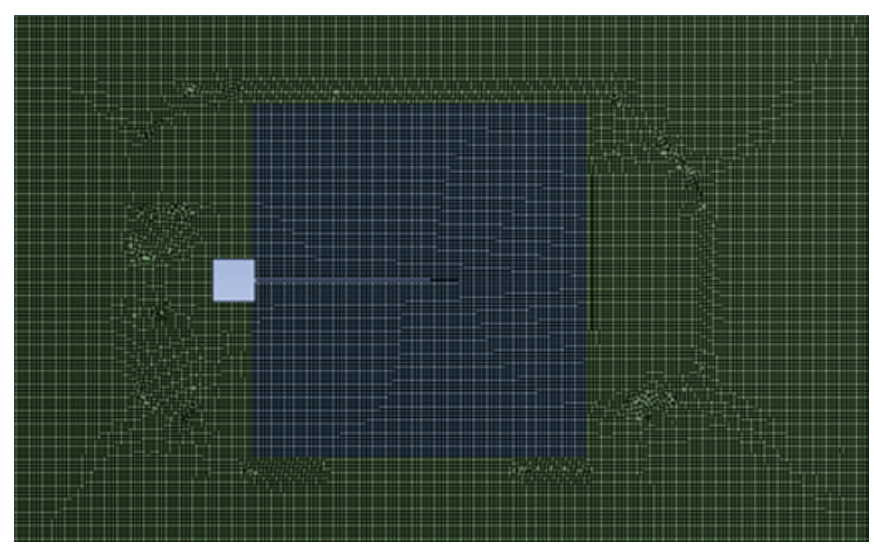

Figure 3

Finite volume mesh for the fluid domain

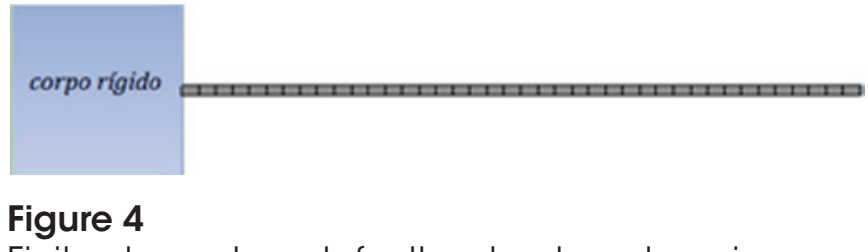

Finite element mesh for the structure domain

The finite volume mesh for the flow is shown in figure 3 , while the finite element mesh of the beam is shown in figure 4. It was decided to use a well-refined quadrilateral mesh in order to obtain more precise results. The fluid domain mesh has 47,854 elements and 23,552 nodes, while the structure domain mesh has 400 elements and 3,053 nodes.

For the coupling, the pressure data was transferred from the fluid to the structure, while the displacement of the structure was transferred to the fluid domain.

\subsection{Modal analysis of a small-scale steel structure}

It is very important to know what the modes of vibration are of a structure and the natural frequency corresponding to each mode. Therefore, in this section, the modal parameters of a steel structure were estimated using the experimental modal analysis method RFP. The results obtained experimentally were compared with the results via FEM.

For the study, three steps were performed: steel structure modeling by the ANSYS ${ }^{\circ}$ software to acquire the modal parameters in the FEM; reading the data and obtaining Frequency Response Functions (FRF) through an experiment and using the Rational Fraction Polynomial method (RFP) for the comparison of results.

\subsubsection{Experiment setup}

In this experiment, a steel structure constructed in the laboratory was used, following the parameters presented in table 1. The structure was fixed by mechanical clamps to simulate a crimping and ensure the boundary conditions in the supports during the measurements. The structure assembly is shown in figure 5. 46 points were measured for vertical and horizontal vibration modes. The transverse modes were not evaluated in this work.

Table 1

Properties of steel structure

\begin{tabular}{ccc}
\hline Properties of steel structure & \multicolumn{2}{c}{ Numeric values } \\
\hline Height $(H)$ & 0.6 & $\mathrm{~m}$ \\
Partial height $(D)$ & 0.15 & $\mathrm{~m}$ \\
Section thickness $(\mathrm{a})$ & 0.00615 & $\mathrm{~m}$ \\
Section lenght $(\mathrm{b})$ & 0.0131 & $\mathrm{~m}$ \\
Density of mass $(\rho)$ & 7,850 & $\mathrm{~kg} / \mathrm{m}^{3}$ \\
Young module (E) & 200 & $\mathrm{GPa}$ \\
Poisson module (v) & 0,26 & - \\
Cross-sectional area $(\mathrm{A}=\mathrm{a} \cdot \mathrm{b})$ & $8.06 \times 10-05$ & $\mathrm{~m}^{2}$ \\
Moment of inertia $\left(\mathrm{I}=\mathrm{b} \cdot \mathrm{a}^{3} / 12\right)$ & $2.54 \times 10-10$ & $\mathrm{~m}^{4}$ \\
\hline
\end{tabular}




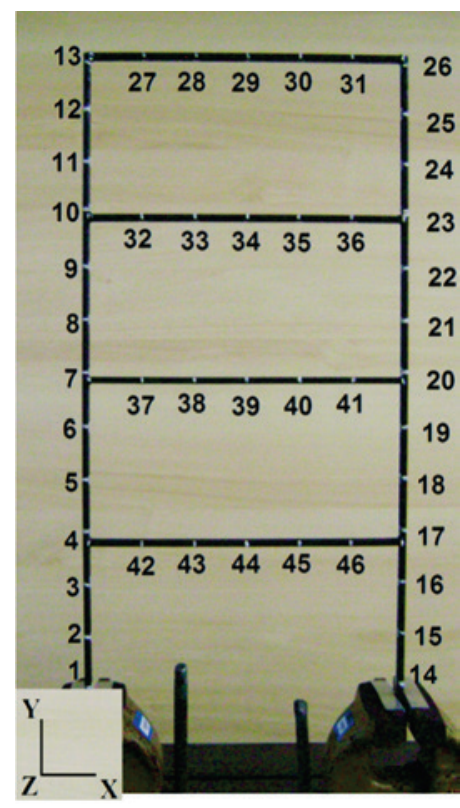

\section{Figure 5}

Steel structure used for the experiment

\subsubsection{Experimental procedure}

Data was acquired using a dynamic vibration analyzer, Figure $6 \mathrm{~b}$. The sampling frequency was fixed at $400 \mathrm{~Hz}$. The input and output signals were filtered through a power window and an exponential decay window respectively, while the resolution of the measurement was $0.25 \mathrm{~Hz}$.

The structure was excited with an impact hammer (Figure 6b) at node 24 , pushing it into the negative direction of the $x$-axis. The hammer has a load cell with a sensitivity of $2.27 \mathrm{mV} / \mathrm{N}$ to detect the magnitude of the excitation force.

The vibration response was measured at all nodes with an accelerometer. The accelerometer was positioned in the structure to measure only the accelerations perpendicular to the surface thereof (Figure 6a).

The RFP method was implemented and inserted into the EasyMod

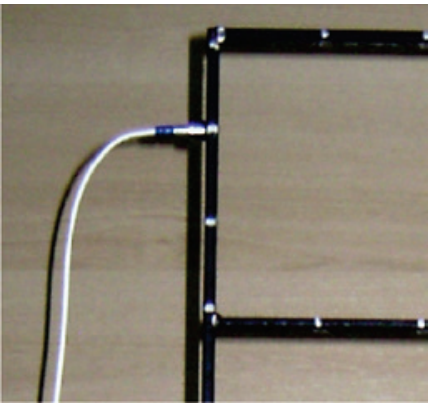

(a)

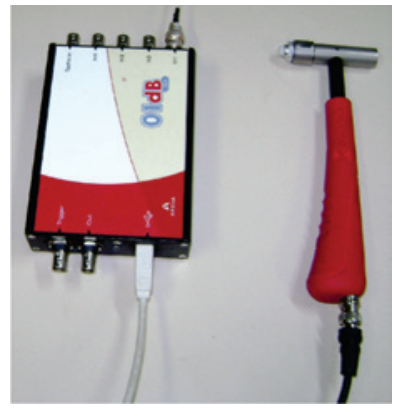

(b)

\section{Figure 6}

(a) Position of the accelerometer and (b) Vibration analyzer and impact hammer
Table 2

Natural frequencies for the first three modes of vibration

\begin{tabular}{cccc}
\cline { 2 - 4 } & \multicolumn{2}{c}{ Method RFP } & FEM \\
\cline { 2 - 4 } & $\begin{array}{c}\text { Frequency } \\
{[\mathrm{Hz}]}\end{array}$ & $\begin{array}{c}\text { Damping } \\
\text { coefficient } \\
{[\%]}\end{array}$ & $\begin{array}{c}\text { Frequency } \\
{[\mathrm{Hz}]}\end{array}$ \\
\hline $1^{\text {st }}$ & 26,302 & 1,2746 & 29,319 \\
$2^{\text {nd }}$ & 92,508 & 0,2440 & 98,771 \\
$3^{\text {rd }}$ & 177,203 & 0,1863 & 191,27 \\
\hline
\end{tabular}

toolbox (Kouroussis, [18]). Thus, it was possible to obtain the experimental modal parameters.

\subsection{Coupled fluid-structure problem}

The case analyzed in this work has the objective of studying the dynamic behavior of a structure subjected to oscillations of pressure loads. To simulate this, a rigid cube-shaped body is submerged in an air flow, generating vortices which, consequently, make the lift coefficient on the structure oscillate. To compare with the vibration modes of the structure, a modal analysis was performed through the ANSYS ${ }^{\circ}$ software, where the modes of vibration and natural frequencies for several similar porticos with different sizes and rigidities were determined. Table 3 gives a summary of this study, while Figure 7 shows the structure and its main dimensions.

It is noticed that the natural frequency of the structure is changed as its dimensions change. For example, a portico $120 \mathrm{~cm}$ high by $60 \mathrm{~cm}$ wide, made with $0.615 \times 1.31 \mathrm{~cm}$ cross-section bars, has a natural frequency close to $7.8 \mathrm{~Hz}$. This was the portico used in the coupled fluid-structure problem simulated and figure 8 shows the model and the boundary conditions.

A similar approach to the case of fluid-structure coupling in section 3.1 of this work was considered. That is, a mobile mesh for the fluid in the region near the structure, constant air inflow, non-slip condition at the contacts between fluid and solid bodies and zero pressure at the outlet. For the generation of the vortices, the flow was blocked by a rigid square shaped body with $100 \mathrm{~cm}$ sides, as was the case of the beam being excited by the fluid flow (item 3.1 of this article). Considering that the lift coefficient generated by the rigid obstacle oscillates

\section{Table 3}

Natural frequencies for the first mode of vibration of the various frames tested by the FEM

\begin{tabular}{ccc}
\hline $\begin{array}{c}\mathbf{H} \mathbf{x} \mathbf{L} \\
(\mathrm{mm})\end{array}$ & $\begin{array}{c}\mathbf{a} \mathbf{\times b} \\
(\mathrm{mm})\end{array}$ & $\begin{array}{c}\text { Natural frequency } \\
\text { of } \mathbf{1}^{\text {st }} \text { vibration } \\
\text { mode }\end{array}$ \\
\hline $1200 \times 600$ & $6.15 \times 13.1$ & 7.8 \\
$1200 \times 600$ & $12.3 \times 26.2$ & 15.9 \\
$1800 \times 900$ & $18.4 \times 39.3$ & 10.6 \\
$2400 \times 1200$ & $24.6 \times 52.4$ & 7.9 \\
$2700 \times 1350$ & $27.7 \times 58.9$ & 7.1 \\
$3000 \times 1500$ & $30.8 \times 65.5$ & 6.4 \\
\hline
\end{tabular}




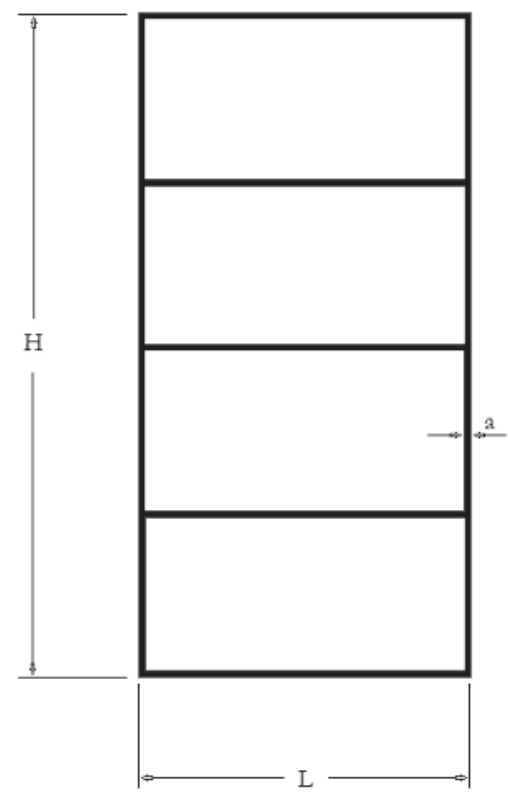

\section{Figure 7}

Structural model with its main measurements of the porch used for modal analysis study

between positive and negative, the portico was positioned "lying down" and set at its right end to cause the lift coefficient to act in a way to oscillate the structure according to its modes of vibration analyzed.

Here, the velocity of entry was controlled and some velocities were tested, monitoring the drag and lift coefficients for each of these velocities. For a velocity $u_{\infty}=80 \mathrm{~m} / \mathrm{s}$ it was found that the oscillation frequency of the lift coefficient on the portico is close to $8 \mathrm{~Hz}$, as well as the natural frequency of the portico. For the fluid, a mesh of 21,162 elements and 21,450 nodes was assembled, whereas for the structure, a mesh of 1,082 elements and 10,192 nodes was constructed. In Figures 9 and 10 , the meshes for the fluid domain and structure are respectively shown.

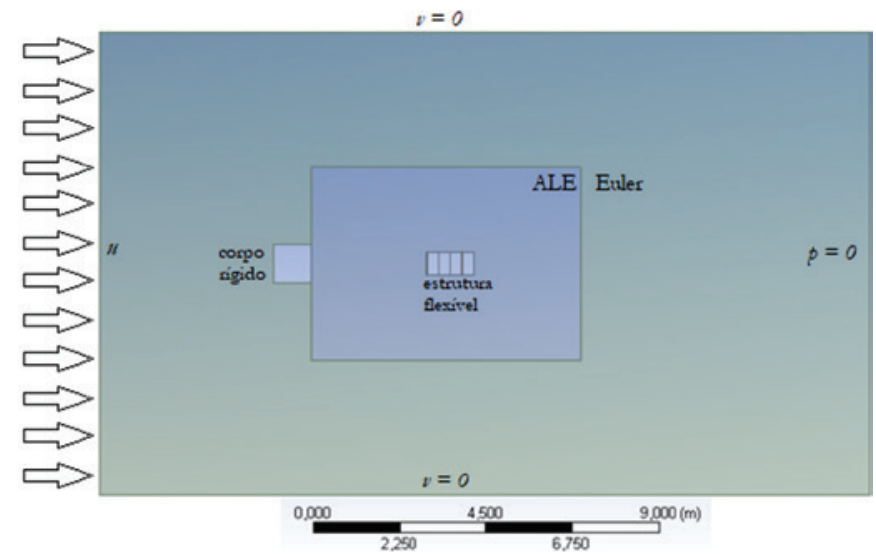

Figure 8

Geometry for the coupled problem

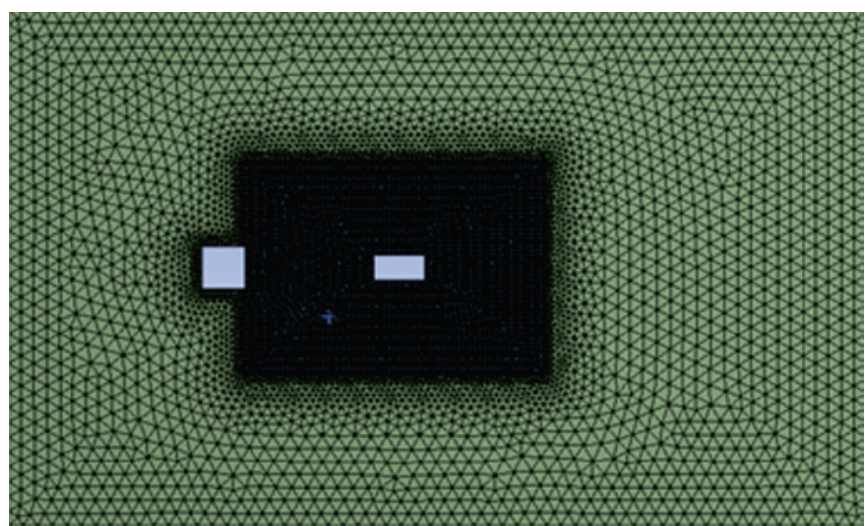

Figure 9

Finite volume mesh for the coupled problem

\section{Results and discussions}

This section will present the results of each of the models presented in the previous section, as well as the relevant discussions.

\subsection{Vibration of a beam induced by a fluid}

The displacement along the vertical direction of the vertex on the right side the beam was monitored. The results obtained by Dettmer and Peric [13] and Wall and Ramm [12] are shown in figures 11 and 12, respectively.

In both cases, the amplitude of the vertical displacement is close to $1.2 \mathrm{~cm}$, while a cycle takes around $0.3 \mathrm{~s}$. It is noticed that the behavior for the two cases are not identical, mainly at the beginning of the flow, which is in transient state. This because each author has developed their own numerical model for the resolution. However, what is noticeable is that after establishing the steady state, the dynamic behavior of the structure is the same.

During the resolution of the coupled problem simulated by the authors of this article, the drag $(\mathrm{Cd})$ and lift $(\mathrm{Cl})$ coefficients on the structure were monitored in addition to the beam displacement. The drag and lift oscillations are shown in Figures 13 and 14. It is

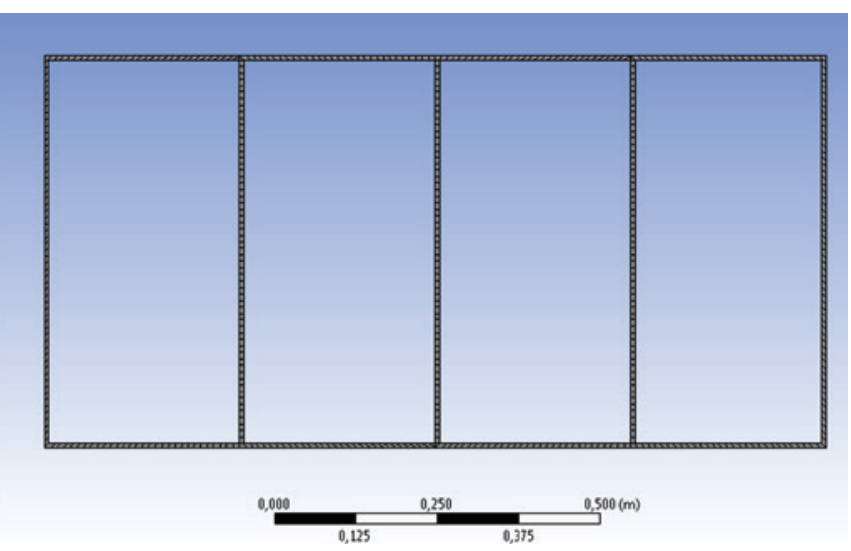

Figure 10

Structure mesh for the coupled problem 
noted that a variation cycle of the $\mathrm{Cl}$ takes approximately the same $0.3 \mathrm{~s}$ as the oscillation cycle of the beam.

The displacement obtained in the simulation of this problem is also in agreement with the works found in the literature, which is shown in Figures 15 and 16 . The oscillation of the beam during the steady flow state of the fluid is shown in Figure 17.

\subsection{Modal analysis of a small-scale steel structure}

The natural frequencies and damping factor for the first three modes of vibration are shown in Table 2, where only the modes in the $x-y$ plane were measured, the other planes being disre-

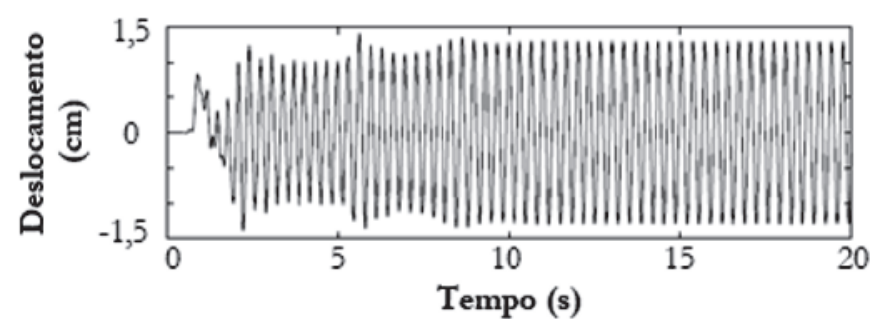

Figure 11

Vertical displacement of the vertex of the structure. Results obtained by Dettmer and Peric [13]

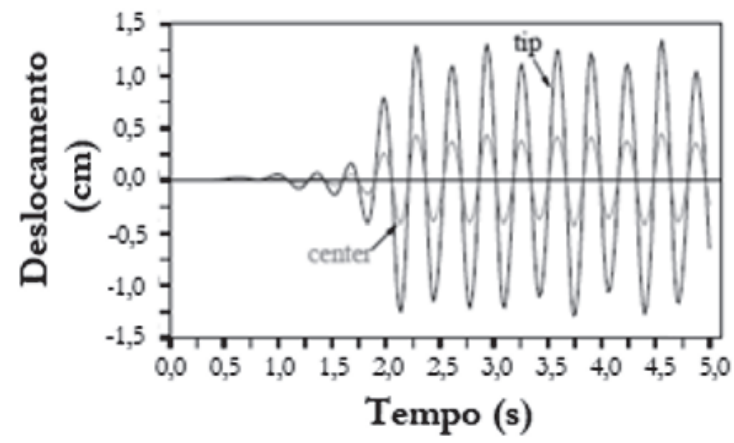

\section{Figure 12}

Vertical displacement of the vertex and the center of the structure. Results obtained by Wall and Ramm [12]

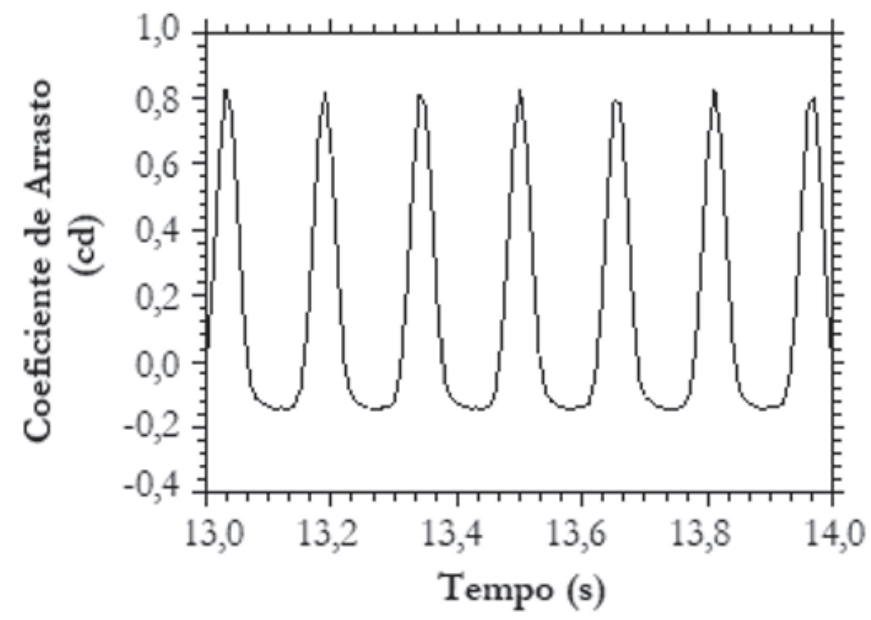

Figure 13

Drag coeficient between 13 and 14 seconds of simulation garded. Regarding the FEM, the results of the natural frequencies of the first, second and third modes of vibration using the RFP method present an error of $10.3 \%, 6.3 \%$ and $7.4 \%$, respectively.

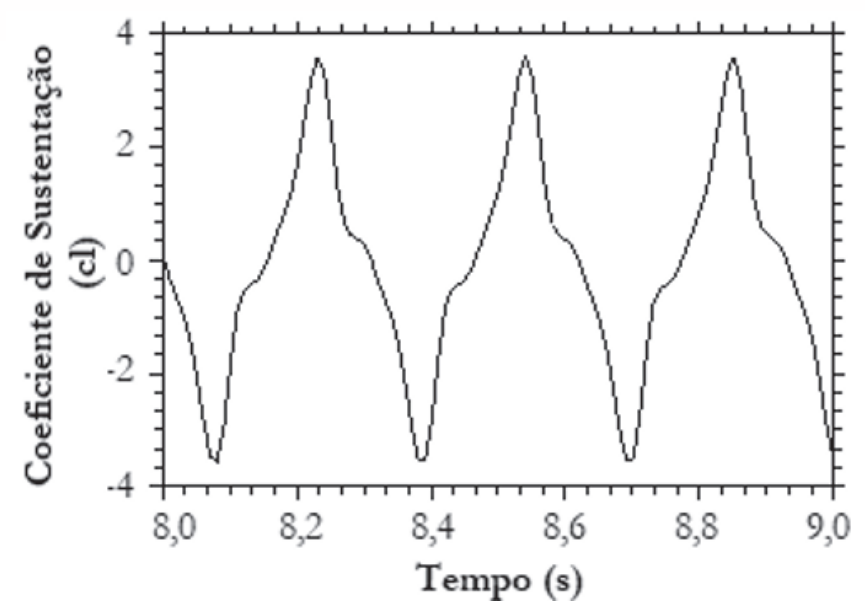

Figure 14

Lift coeficient between 8 and 9 seconds

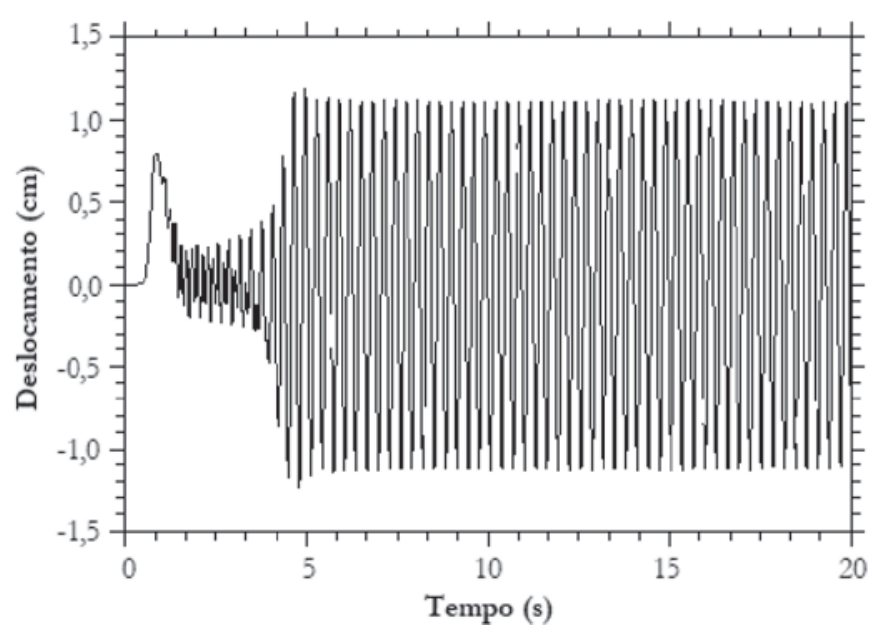

Figure 15

Displacement of the right vertex of the beam over time

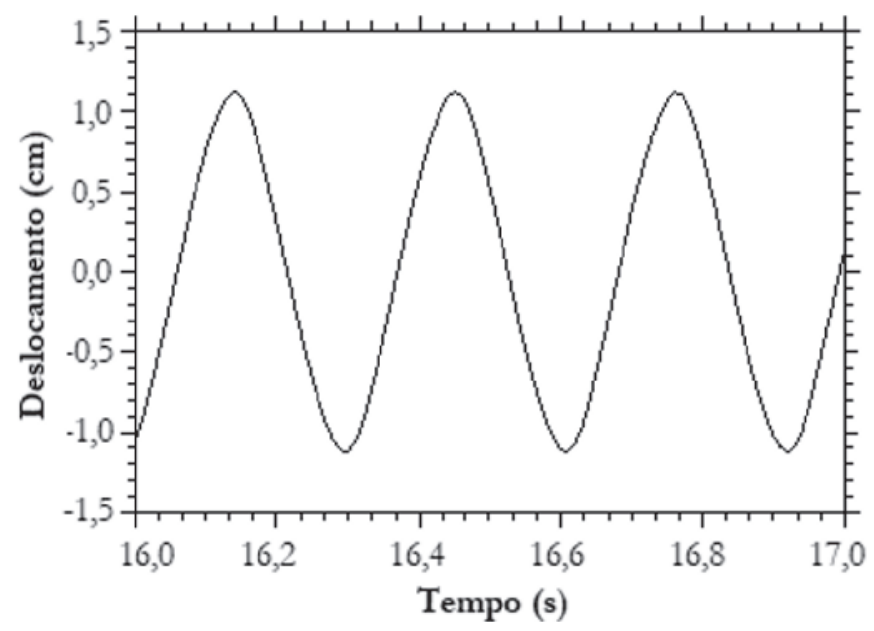

Figure 16

Displacement of the right vertex of the beam between 16 and 17 seconds of simulation 


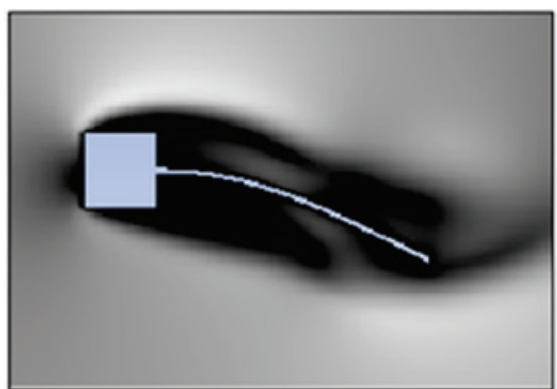

$\mathrm{t}=4,81 \mathrm{~s}$

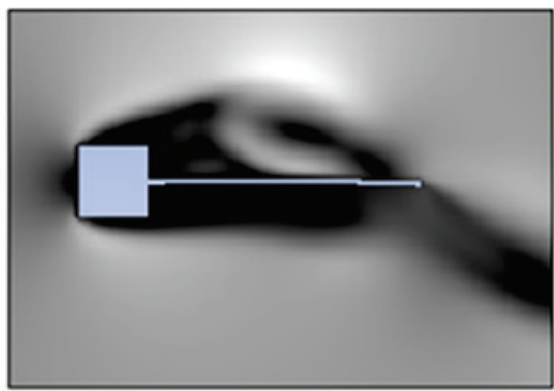

$\mathrm{t}=4,89 \mathrm{~s}$

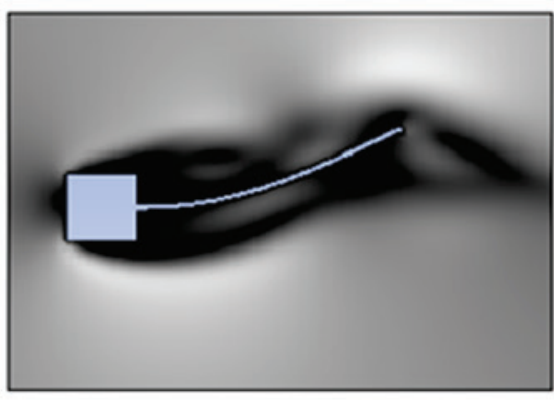

$\mathrm{t}=4,97 \mathrm{~s}$

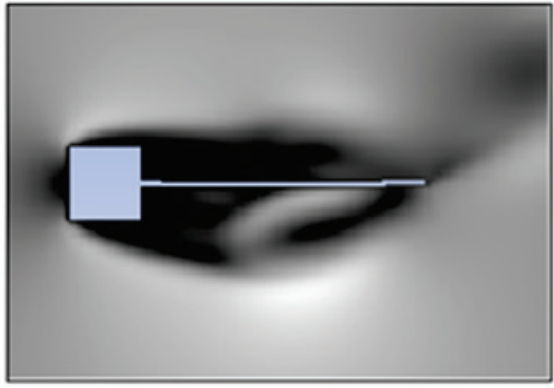

$\mathrm{t}=5,05 \mathrm{~s}$

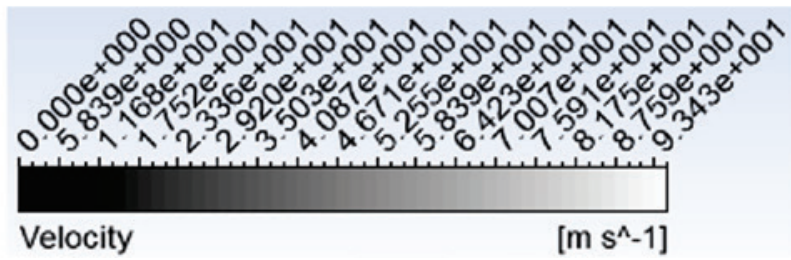

$\mathrm{t}=4,85 \mathrm{~s}$

$\mathrm{t}=4,93 \mathrm{~s}$

$\mathrm{t}=5,01 \mathrm{~s}$

$\mathrm{t}=5,10 \mathrm{~s}$

Figure 17
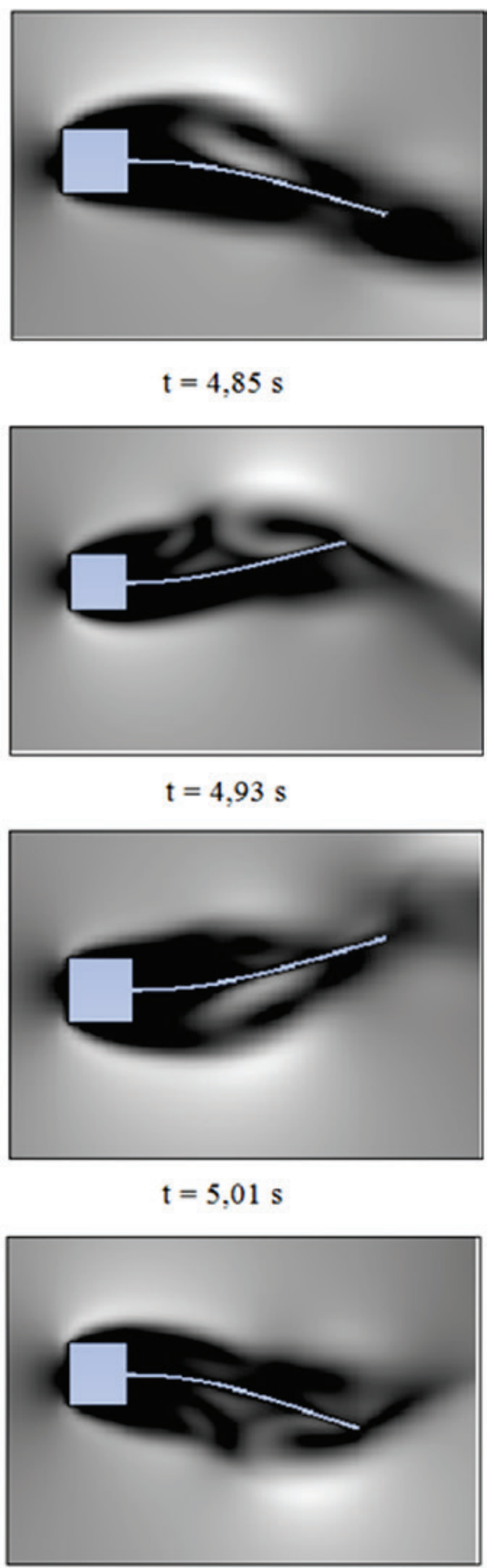

Vibration of a beam induced by a fluid flow 

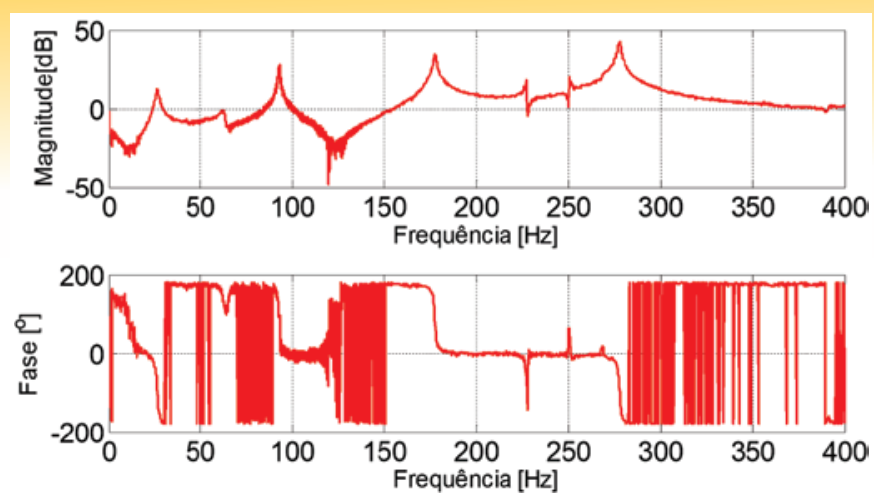

Figure 18 shows the experimental Frequency Response Function (FRF) of point 3.

Figure 19 shows the vibration modes obtained by the RFP method with the experimental data and by the FEM using the ANSYS $®$ software.

As shown, the results obtained by the RFP method are compatible with the FEM, although the natural frequencies have a small dispersion in the values when the two methods are compared. This can be attributed to the following factors: geometric divergences between the actual portico and the modeling in the analytical method; the result obtained by the FEM does not consider the damping factor; the RFP method suffers external influences that are not controllable at the moment of data collection, interfering with the final results.

The validation of the numerical modeling used by the ANSYS $₫$ software was effective when comparing its results with the experi-

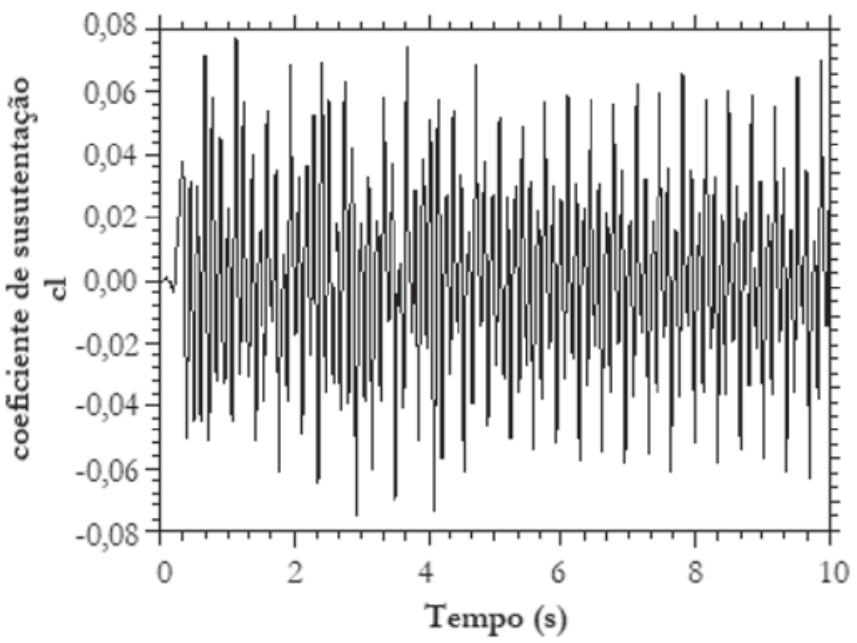

Figure 20

Lift coefficient on the Portico x Time

$2^{\circ}$ modo: $92,508 \mathrm{~Hz}$

(b)

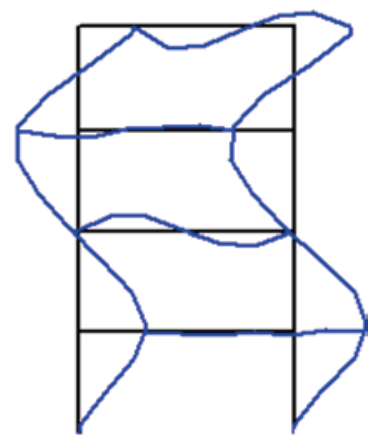

$3^{\circ}$ modo: $177,203 \mathrm{~Hz}$ (c)

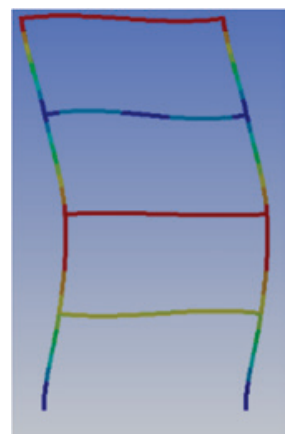

$2^{\circ}$ modo: $98,771 \mathrm{~Hz}$

(e)

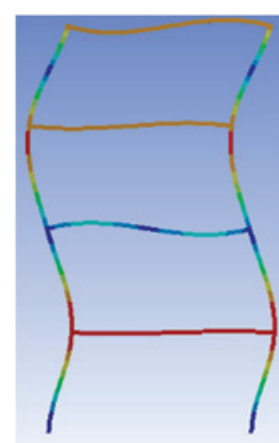

$2^{\circ}$ modo: $191,270 \mathrm{~Hz}$

(f)

Figure 19

Vibration mode: (a), (b), (c) by RFP; (d), (e), (f) by FEM (ANSYS)

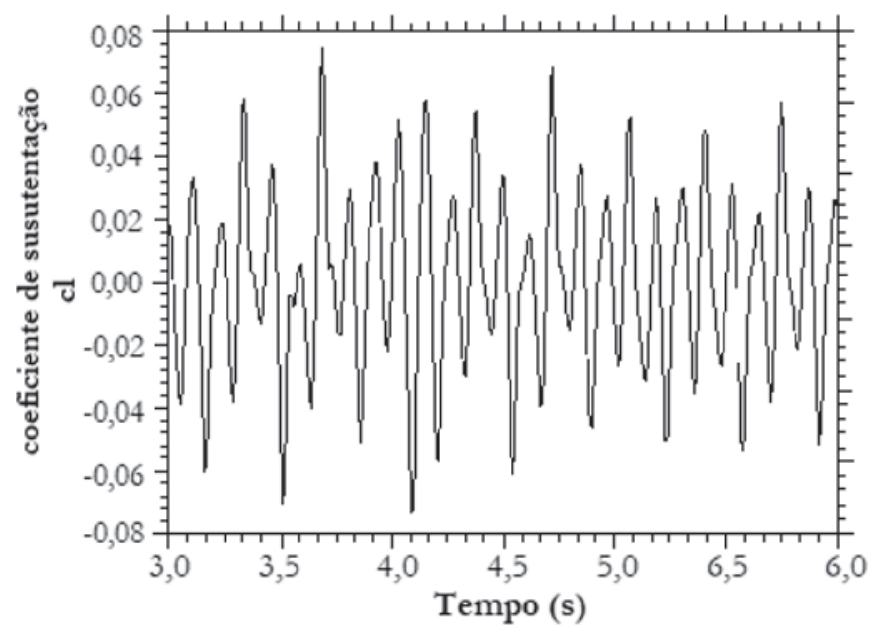

Figure 21

Lift coefficient on the Portico between 3 and 6 seconds 
mental results. In this way, numerical modeling was used to perform the modal analysis of the structure presented in the sequence of this work.

\subsection{Coupled fluid-structure problem}

In this study, it was sought to balance the frequency of oscillations of the lift coefficient with the natural frequency relative to the 1st mode of vibration of a portico. The portico chosen and the problem were those previously modeled.

The drag coefficient in this case is not important, since the vertical displacement of the upper left vertex of the portico was monitored. The interesting thing is the behavior of the lift coefficient on the portico, which is responsible for the vertical displacements on the structure. Figures 20 and 21 show the behavior of the lift coefficient, which varies with average null value and with amplitude of up to 0.075 . Its oscillation frequency is close

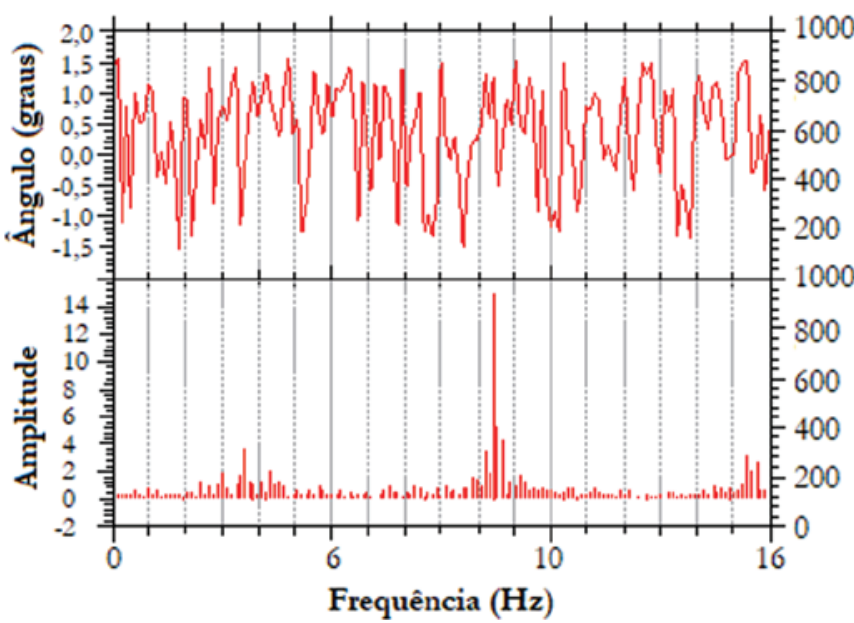

Figure 22

FFT for the Lift coefficient

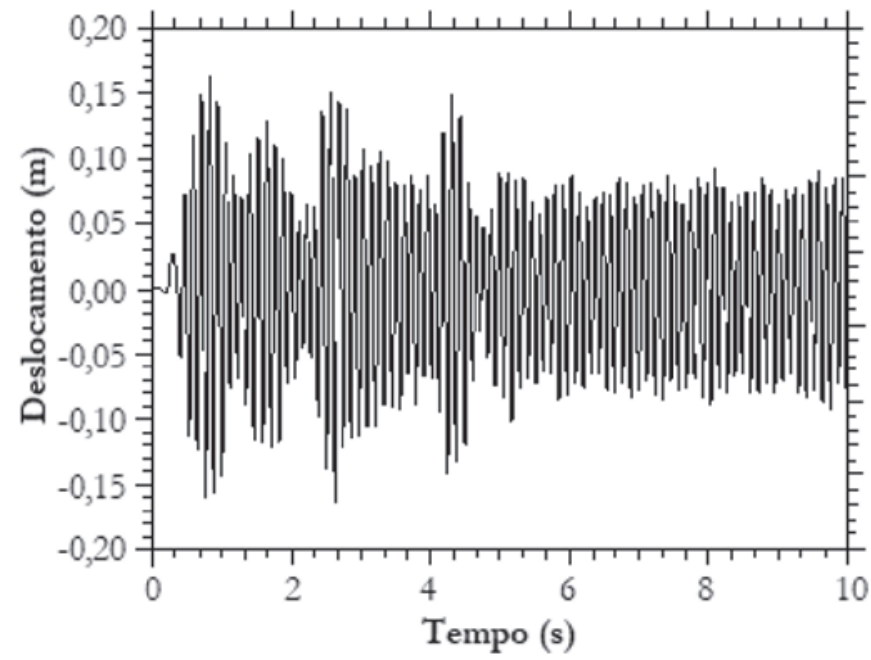

Figure 23

Displacement of the Upper left vertex x Time to $8.8 \mathrm{~Hz}$, according to its Fast Fourier Transform (FFT) shown in figure 22

The graph of the FFT for the lift coefficient shows that the oscillation frequency of this is $8.8 \mathrm{~Hz}$. This frequency is very close to the natural frequency of the analyzed portico, which is $7.9 \mathrm{~Hz}$. One can imagine that the portico is vibrating according to its first mode of vibration.

To verify this, it is necessary to analyze the behavior of the portico displacement. The vertical displacement of the upper left vertex is shown in Figures 23 and 24. Finally, in Figure 25, it can be seen that the frequency taken from the FFT of the actual displacement of the structure registers a frequency of $8.8 \mathrm{~Hz}$, as well as that of the lift coefficient.

In this case, it was observed that the displacement increases in

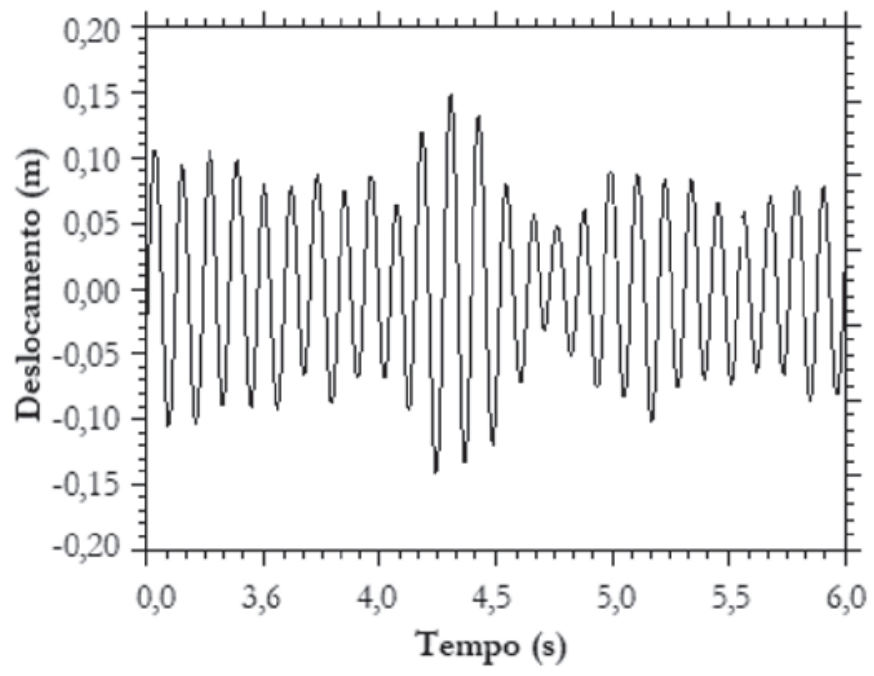

Figure 24

Displacement of the Upper left vertex between 3 and 6 seconds

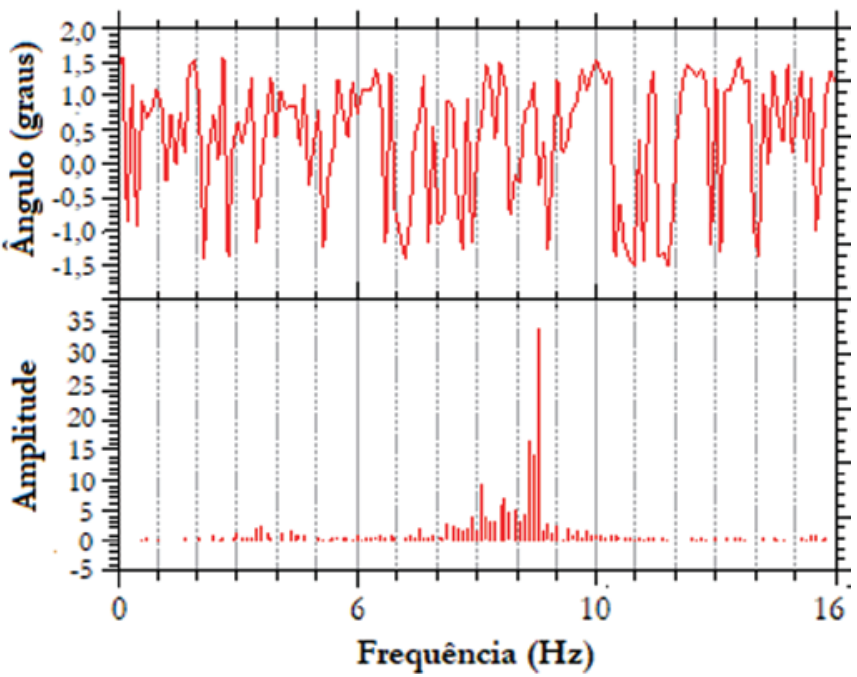

Figure 25

FFT for the Upper left vertex displacement 
amplitude in each cycle until a certain moment, reaching a maximum displacement around 17 centimeters. After reaching this maximum amplitude, it begins to decay again, and this amplitude variation persists until the steady state is established. Figure 26 illustrates this behavior. Furthermore, in this figure, it is observed that the structure vibrates according to its first mode of vibration, and also that the amplitude of the displacement increases in each cycle up to $4.32 \mathrm{sec}-$ onds, then gradually decreases up to 4.45 seconds. After $4.50 \mathrm{sec}-$ onds, the amplitude starts increasing again and so on until the steady state is reached.

\section{Conclusions}

In this work, a coupled fluid-structure problem was approached, comparing the result with the modal analysis of a structure. For this, an experimental and numerical approach was performed, that is, the experimental results were used for validation of numerical modeling. The conclusions of each case addressed in the paper are presented below.

\subsection{Vibration of a beam induced by a fluid}

After performing a comparative analysis of a problem found in the literature, it is concluded that the model adopted for solving a coupled fluid-structure problem, where the structure is flexible and the Newtonian fluid, presents results compatible with the numerical models developed in the references. This model is adopted by ANSYS $®$ multi-physical analysis software, used in case simulations.

\subsection{Modal analysis of a small scale steel structure}

As presented, the results obtained by the RFP method are compatible with the FEM, although the natural frequencies have a small dispersion in the values when the two methods are compared. This can be attributed to the following factors: geometric divergences between the actual portico and the model in the analytical method; the result obtained by the FEM does not consider the damping factor; the RFP method undergoes external influences that are not controllable at the moment of data collection, interfering with the final results. These results validate the numerical modeling used in the ANSYS $\otimes$ software. Therefore, it is valid to use this for modal analysis of the structure approached in the next case.

\subsection{Coupled fluid-structure problem}

The coupled problem consists in analyzing the dynamic behavior
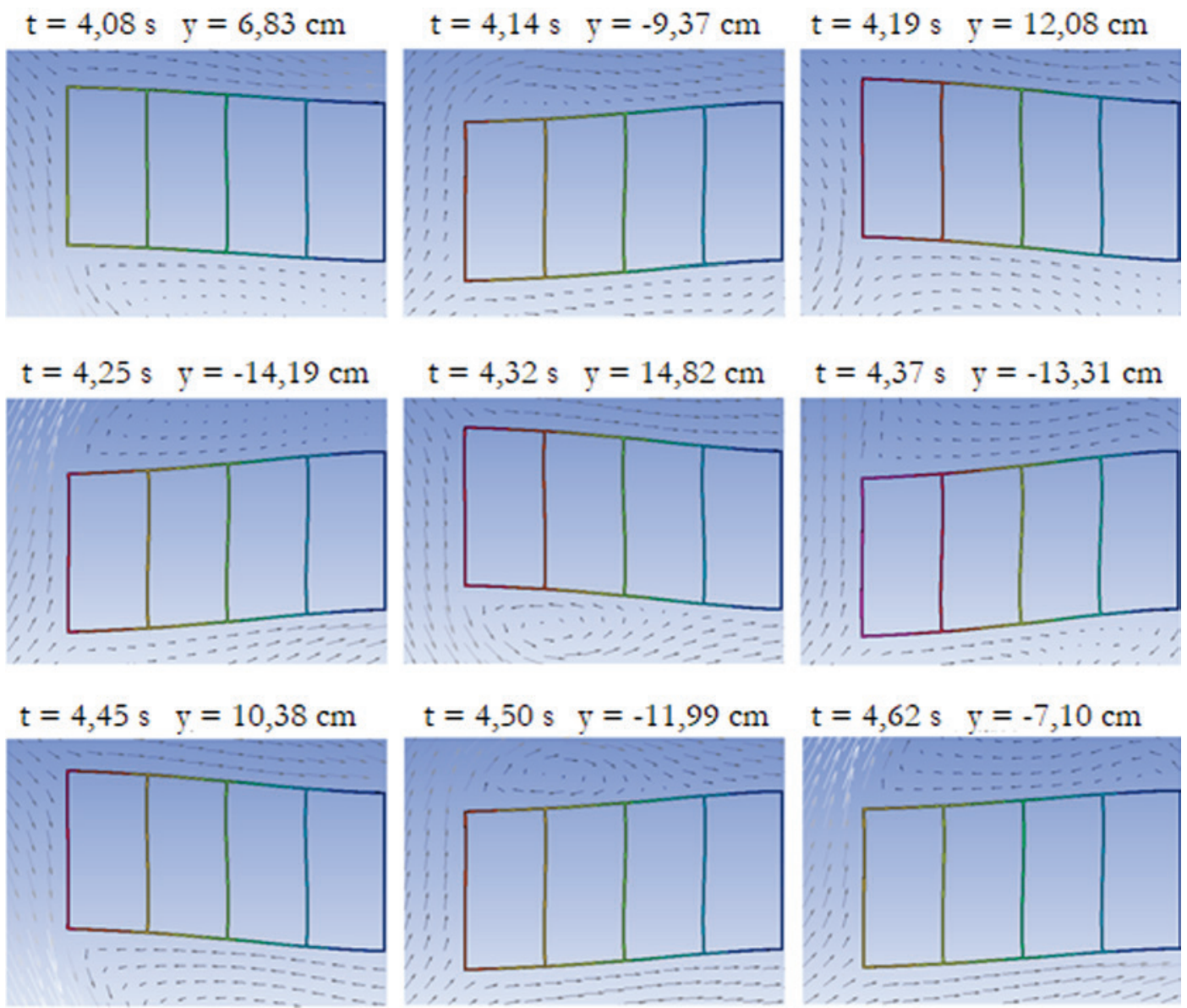

\section{Figure 26}

Oscillatory motion of the structure, where: $t$ is the simulation time and $y$ is the vertical displacement of the upper left vertex of the structure 
of the structure when it is subjected to an oscillatory lift coefficient, generated by the incidence of an airflow in obstacles. It was verified that a structure submitted to this type of flow tends to move according to its modes of vibration.

Finally, it is added that the advancement of computational mechanics is allowing the resolution of complex problems in a timely manner and this can be incorporated into structural projects. There is still a long and arduous path of research to be done to make this habitual. However, it is believed that the consideration of the dynamic effects in light structures can bring more accurate results of the phenomena that involve these structures, and make them safer and more economical at the same time.

\section{Acknowledgments}

The authors of this paper thank UTFPR - Federal University of Technology - Paraná - Pato Branco Campus - Pato Branco Campus, for the resources available to carry out this research and CAPES, for financial support to the first author. The authors would also like to thank the Araucária Foundation for Support for Scientific and Technological Development, for the financial support granted - Notice 24/2012 Basic and Applied Research Program (FUNTEF-PR 376/2014).

\section{References}

[1] Souza JR., L. C. Uma Aplicação dos Métodos dos Elementos Finitos e Diferenças Finitas à Interação Fluido-Estrutura. Dissertação de Mestrado em Estruturas e Construção Civil, Publicação E.DM-008/06, Departamento de Engenharia Civil e Ambiental, Universidade de Brasília, DF, 2006, 197p.

[2] Gilbert, R. J. "Vibrations des structures - Interactions avec les fluids - Sources d'excitation aléatoires". E. Eyroller, Paris, França, 1988.

[3] Zienkievicz, O. C. e Taylor, R. L. "The Finite Element Method", Fourth Edition, McGraw-Hill, Pub. Co. Ltd. UK, vol.2, 1989.

[4] Junger, M.C. "Acoustic fluid-elastic structure interactions: basic concepts." In: Computers \& Structures, vol. 65, n 3 , 287-293, 1997.

[5] Tabarrok, B. "Dual formulations for acoustic-structural vibrations." In: International Journal for Numerical Methods in Engineering, vol. 13, 197-201p, 1978.

[6] Leitão, G. B. Análise Numérica de Segunda Ordem de Pórticos Planos de Estruturas de Aço. Dissertação de Mestrado em Estruturas, Curso de Pós Graduação em Engenharia Civil, UNICAMP, Campinas, SP, 2014.

[7] Everstine, C.G. "Finite elemento formulations of structural acoustics problems." In: Computers \& Structures, vol. 65, $\mathrm{n}^{\circ}$ 3, 307-321p, 1997.

[8] Gomes, F.A.A. Análise Numérica do Escoamento Hipersônico em Torno de Corpos Rombudos Utilizando Métodos de Alta Ordem. Tese de Doutorado - Instituto Tecnológico de Aeronáutica, São José dos Campos. 2012.

[9] Soares Jr, D. Análise Dinâmica de Sistemas Não-lineares com Acoplamento do Tipo Solo-fluido-estrutura por Intermédio dos Métodos dos Elementos Finitos e do Método dos
Elementos de Contorno. Tese de Doutorado em Engenharia Civil - Universidade Federal do Rio de Janeiro, 2004.

[10] Bazilevs, Y., Takizawa, K., and Tezduyar, T. E. "Computational fluid-structure interaction: methods and applications". John Wiley \& Sons. 2013.

[11] Zienkievicz, O. C. e Bettess, P. "Fluid-structures dynamics interaction and wave forces. An introduction to numerical treatment. International Journal for Numerical Methods in Engineering, 13.1, 1-16p. 1978.

[12] Wall, W. A. e Ramm, E. "Fluid-structure interaction based upon a stabilized (ALE) finite elemento method". Computational mechanics. New Trends and Applications. S.R. Idelsohn, E. Oñate and E.N. Dvorkin (Eds). CIMNE, BarceIona, Spain, 1998.

[13] Dettmer, W., Peric, D. "A computational framework for fluidstructure interaction: Finite elemento formulation and applications". Computational Methods Appl. Mech. Engrg. 195 5754-5779, 2005.

[14] Teixeira, P. R. F. e Awruch, A. M. "Numerical simulation of fluid-structure interaction using the finite elemento method". Computers \& Fluids. 34, 249-273, 2004.

[15] Ewins, D. J., 2000. "Modal Testing: Theory, Practice and Application". John Wiley, Philadelphia, 2nd edition.

[16] Schwarz, B. e Richardson, M. H. "Experimental Modal Analysis. In: CSI Reliability Week, 1999. Proceedings: Jamestown, Califórnia, 1999.

[17] FLUENT v6.3, Fluent Incorporate Inc., Centerra Resource Park, 10, Cavendish Court, Lebanon, New Hampshire, USA, 03766, 2006.

[18] Kouroussis, G., Bem Fekih, L., Conti, C., Verlinden, O. "EasyMod: a matlab / scilab toolbox for teaching modal analysis". Proceedings of the 19th International Congresso on Sound and Vibration, Vilnius (Lituânia), July 9-12, 2012. 